\title{
Remerciements Acknowledgements
}

Volume 50, numéro 1, 1983

Bilan de l'histoire religieuse au Canada

Canadian Catholic History: A survey

URI : https://id.erudit.org/iderudit/1007031ar

DOI : https://doi.org/10.7202/1007031ar

Aller au sommaire du numéro

Éditeur(s)

Les Éditions Historia Ecclesiæ Catholicæ Canadensis Inc.

ISSN

0318-6172 (imprimé)

1927-7067 (numérique)

Découvrir la revue

Citer ce document

(1983). Remerciements / Acknowledgements. Sessions d'étude - Société

canadienne d'histoire de l'Église catholique, 50(1), 5-6.

https://doi.org/10.7202/1007031ar

Tous droits réservés @ Les Éditions Historia Ecclesiæ Catholicæ Canadensis Inc., 1983
Ce document est protégé par la loi sur le droit d'auteur. L'utilisation des services d'Érudit (y compris la reproduction) est assujettie à sa politique d'utilisation que vous pouvez consulter en ligne.

https://apropos.erudit.org/fr/usagers/politique-dutilisation/ 


\section{Remerciements / Acknowledgements}

Ce congrès et la publication des Actes n'auraient pas été possibles sans l'aide généreuse de la Fondation Jackman, du Conseil de recherches en Sciences humaines du Canada, de la Conférence des évêques catholiques du Canada et de l'Université Saint-Paul.

It would have been impossible to hold our Congress and publish these Volumes without the generous help of the Jackman Foundation, The Social Science and Humanities Research Council, the Canadian Catholic Conference of Bishop and Saint Paul University.

Nous remercions aussi les personnes suivantes:

We also wish to extend our gratitude to the following persons:

\section{ORGANISATION DU CONGRÈS / CONGRESS ORGANIZATION}

\begin{tabular}{|l|}
\hline Comité général / General Committee \\
Pierre Hurtubise, o.m.i., Section francaise \\
Edward Jackman, o.p., Section anglaise \\
Guy LaPerrière, Section française \\
Margaret Mattson, Section anglaise \\
\hline Comité local / Local Committee \\
Claudette Lacelle, présidente \\
Victorin Chabot, programme \\
Margaret Mattson, programme \\
Ghislaine Ritchot, officier de liaison \\
Jean-Jacques Robillard, o.p., publiciste \\
James Whalen, publiciste
\end{tabular}

Président(e)s de séances / Chairpersons

Andrée Désilets

Susan Mann Trofimenkoff Brian Hogan, C.S.B. Raymond Huel Louis Rousseau Robert W. Michel Terry Murphy Alphonse de Valk, C.S.B. Maureen Slattery Gerald J. Stortz 
Communications non-publiées / Unpublished papers:

Edward Jackman, o.p.: The Role and Methodology of Local and Regional Catholic Historiography in Canada

Thomas M. Landry, o.p.: L'Église catholique canadienne-française et les francophones de la Nouvelle-Angleterre, 1870-1930.

Philippe Sylvain: La formation du clergé canadien-français au $\mathrm{XIX}^{\mathrm{e}}$ siècle. 